\title{
Neuropsychiatric, cognitive and sexual impairment in mastocytosis patients
}

\author{
Fatma Jendoubi ${ }^{1}$, Maella Severino-Freire', Mathilde Negretto' ${ }^{1}$, Christophe Arbus ${ }^{2}$, Carle Paul ${ }^{1}$ \\ and Cristina Bulai Livideanu ${ }^{1 *}$ (B)
}

\begin{abstract}
Background: Mastocytosis is a rare disease characterised by the accumulation and/or proliferation of abnormal mast cells (MCs) in one or several organs. It may present with a number of different symptoms that involve various organ systems. The current study aims to assess the prevalence of MC mediator-related symptoms in a cohort of mastocytosis patients with a specific focus on neurological, psychiatric, cognitive and sexual symptoms. We also assessed the impact of the disease on patients' professional lives. Patients were administered a validated multidimensional questionnaire to collect information on patients' perception of the severity of their symptoms. From the questionnaires we extracted the neurological, cognitive, psychiatric and sexual symptoms and the impact of the disease on patients' professional lives as well as their grading. The affective status was assessed using the 17-item version of the Hamilton Depression Rating Scale.

Results: We included 139 patients. Mastocytosis was classified as systemic in 113 patients and cutaneous in 26 patients. The prevalence of MC mediator-related systemic symptoms was as follows: cutaneous (71\%), gastrointestinal (48\%), cardio-vascular (36\%), musculoskeletal (26.6\%), fatigue (24\%), urinary (14.4\%) and respiratory (10\%). Headaches and vertigo were noted in respectively $55 \%$ and $32 \%$ of patients. Irritability, episodes of memory loss and difficulty concentrating were reported in $54 \%, 52 \%$ and $40 \%$ of cases, respectively. Sexual impairment was noted in $24 \%$ of patients. No associations were found between neuropsychiatric/cognitive impairment and age, gender, diagnostic delay, disease form, the presence of cutaneous lesions, the level of serum and bone marrow tryptase and the presence of KIT mutation in bone marrow and/or skin. Depression was noted in $49 \%$ of patients. One in four patients reported a negative impact of the disease on their professional lives.
\end{abstract}

Conclusion: This current study provides some insights regarding symptoms related to mastocytosis and their impact on patients' professional lives.

Keywords: Mastocytosis, Mast cell mediator-related symptoms, Mast cells

\section{Introduction}

Mastocytosis defines a heterogeneous group of disorders characterised by the accumulation and/or proliferation of abnormal mast cells (MCs) in one or several organs

\footnotetext{
${ }^{*}$ Correspondence: livideanu.c@chu-toulouse.fr

${ }^{1}$ Mastocytosis National Expert Centre (CEREMAST), Department

of Dermatology, Toulouse University Hospital, 24 Chemin de Pouvourville, 31059 Toulouse, France

Full list of author information is available at the end of the article
}

[1]. It is considered an orphan disease with a reported incidence of approximately 0.89 new cases per 100000 inhabitants [2].

Mastocytosis occurs in two major forms: isolated cutaneous mastocytosis (ICM) and systemic mastocytosis (SM) [3].

The diagnosis of SM is established by evidence of MC infiltration in the bone marrow, liver, spleen or gastrointestinal tract. Whereas ICM is characterised by the presence of specific skin lesions and the absence of $\mathrm{MC}$

c) The Author(s) 2021. This article is licensed under a Creative Commons Attribution 4.0 International License, which permits use, sharing, adaptation, distribution and reproduction in any medium or format, as long as you give appropriate credit to the original author(s) and the source, provide a link to the Creative Commons licence, and indicate if changes were made. The images or other third party material in this article are included in the article's Creative Commons licence, unless indicated otherwise in a credit line to the material. If material is not included in the article's Creative Commons licence and your intended use is not permitted by statutory regulation or exceeds the permitted use, you will need to obtain permission directly from the copyright holder. To view a copy of this licence, visit http://creativecommons.org/licenses/by/4.0/. The Creative Commons Public Domain Dedication waiver (http://creativecommons.org/publicdomain/zero/1.0/) applies to the data made available in this article, unless otherwise stated in a credit line to the data. 
infiltration of internal organs [4], SM is further subdivided into indolent forms, characterised by the absence of organ dysfunction (indolent SM, smouldering SM) and advanced, life-threatening forms (aggressive SM, SM with associated clonal haematological non-mast cell lineage disease, MC leukaemia). ICM is most commonly seen in children whereas in adults, cutaneous involvement is mostly associated with SM (85\%) [3].

Mastocytosis may present with several different symptoms due to the uncontrolled proliferation of MCs, the involvement of distinct organs (central nervous system, GI tract, skeleton, bone marrow) or the release of systemic mediators. The latter are referred to as MC mediator-related symptoms. MCs produce and release several clinically relevant mediators such as tryptase, histamine, leukotrienes, proteases, or heparin. Various organ systems are involved including the skin (pruritus, urticarial eruption, angioedema and flushing), the gastrointestinal tract (nausea, cramping and diarrhoea), the respiratory system (shortness of breath, chest tightness, and cough), the cardiovascular system (palpitations, severe anaphylaxis), the urinary system (pollakiuria, nycturia), the musculoskeletal system (pain) and fatigue.

In addition to MC mediator-related systemic symptoms, patients frequently report neurological (headaches, vertigo), cognitive (memory loss, difficulty concentrating), psychiatric symptoms (depression, irritability) and also sexual impairment (erectile dysfunction and dyspareunia). Such symptoms can have a major impact on patients' personal and professional lives [5].

The current study aims to assess the prevalence of MC mediator-related symptoms in a cohort of mastocytosis patients with a specific focus on neurological, psychiatric, cognitive and sexual symptoms. We also assessed the impact of the disease on patients' professional lives.

\section{Materials and methods}

\section{Study population}

We included all adult patients who were part of the ongoing pathophysiological AFIRMM study (Association Française pour les Initiatives et la Recherche sur le Mastocyte et les Mastocytoses). The study was approved by the Institutional Review Board of the Necker EnfantsMalades Hospital on November 8, 2000 (RC31/17/0095) and was carried out in accordance with the Declaration of Helsinki. All patients gave their written informed consent. Patients included in the study were diagnosed with mastocytosis between January 2006 and June 2019 at the Reference Centre of Mastocytosis in Toulouse in France.

\section{The AFIRMM questionnaire}

Patients were administered a multidimensional questionnaire designed by the AFIRMM to collect information on patients' perception of the severity of their symptoms and how these impacted the quality of life. This validated questionnaire was designed on the basis of patient interviews to include the most commonly reported symptoms [6]. The 2.2 version used in our study includes a total of 52 symptoms forming 15 categories (skin, allergy, anaphylactic shock, flush, gastrointestinal tract, rheumatology, constitutional symptoms, cardiology, neurology/psychiatry, respiratory, urology, infection/inflammation, libido/desire, endocrinology and social life).

Patients graded each applicable disability with a score between 0 and 4 ( 0 : Not disabling; 1: mild; 2: moderate; 3: severe; 4: intolerable).

We extracted the following symptoms and their grading from the questionnaires:

- Neurological symptoms: headache, vertigo

- Cognitive symptoms: memory loss, difficulty concentrating

- Psychiatric symptoms: irritability

- Sexual symptoms: erectile dysfunction for male and dyspareunia for female patients

- The impact on professional life: a score ranging from 1 to 4 was considered to correspond to a negative impact.

\section{The HAMILTON score}

The affective status was assessed using the 17-item version of the Hamilton Depression Rating Scale (HDRS17) [7].

Patients were categorised as follows [8]:

- No depression: 0-7

- Mild depression: 8-16

- Moderate depression: 17-23

- Severe depression: $\geq 24$

In addition to data retrieved from the AFIRMM questionnaire and the Hamilton score, we also extracted the following from patients' medical files:

\section{Epidemiological data}

- Age

- Sex

- Age at onset of symptoms, age at diagnosis and diagnostic delay (Calculated by subtracting the age at onset of symptoms from the age at diagnosis) 


\section{Clinical data}

- Mastocytosis form: All patients were diagnosed according to the WHO classification criteria [4]

- History of depression or use of anti-depressants

- Treatments targeting MC mediator-related symptoms

- Other MC mediator-related symptoms: cutaneous, cardio-vascular, gastrointestinal, urinary, respiratory and musculoskeletal symptoms and fatigue

- The presence of cutaneous lesions

\section{Laboratory data}

- Serum and bone marrow tryptase levels

- KIT mutation status in skin and bone marrow

\section{Statistical analysis}

Statistical analyses were performed using the $\mathrm{R}$ statistics software version 3.6.1 (2019-07-05). Quantitative variables were summarised using the following descriptive statistics: median with minimum, maximum. Qualitative variables were compared using the Chi-square test. Normally distributed quantitative variables were compared using Student's $t$-test. Normally distributed quantitative variables were compared using Wilcoxon's test. Relative risk and confidence intervals were used to analyse associations between neurological, cognitive, psychiatric, sexual symptoms, the impact on professional life and the epidemiological, clinical and laboratory data using the "EpiR" Package (Epi version 2.40).

\section{Results}

Of the 220 patients diagnosed with mastocytosis and registered in our database, 139 had completed the AFIRMM questionnaire (78 female and 61 male).

The mean age was 48 years [range 17, 92]. Mastocytosis was classified as SM in 113 patients (Indolent: 88, advanced: 25) and ICM in 26 patients. Among patients with SM, 117 (80\%) had cutaneous involvement. The median serum tryptase level was $21.8 \mu \mathrm{g} / \mathrm{l}$ [range 1-338] and the median medullar tryptase level was $104 \mu \mathrm{g} / \mathrm{l}$ [range 1.6-41,085]. KIT mutations were detected in the skin and bone marrow of $72 \%$ and $77 \%$ of patients, respectively.

At the time of the study, $56 \%$ of patients were undergoing an anti-histamine, and/or anti-leukotriene treatment. The median age at which symptoms were first observed was 48 years [range 17-92]. Median time to diagnosis was 4.5 years [range $0-35$ years]. A previous medical history of depression was noted in $27 \%$ of patients and $13 \%$ of patients were undergoing pharmacological therapy for depression at the time they completed the questionnaire.

MC mediator-related systemic symptoms were noted in $85 \%$ of patients. Their prevalence was as follows: cutaneous (71\%), gastro-intestinal (48\%), cardio-vascular (36\%), musculoskeletal (26.6\%), fatigue (24\%), urinary (14.4\%) and respiratory (10\%).

The prevalence and the severity of neuro-psychiatric, cognitive, and sexual symptoms and the impact on professional life, evaluated from the AFIRMM questionnaires, are shown in Table 1.

Among neurological symptoms, headaches were noted in $55 \%$ of patients and vertigo in $32 \%$ of patients. Approximately one half of patients suffered psycho-cognitive impairment with irritability, episodes of memory loss and difficulty concentrating reported in $54 \%, 52 \%$ and $40 \%$ of cases, respectively. Neurological, psychiatric, and cognitive impairment in our cohort was considered as mild to

Table 1 Prevalence and severity of neuro-psychiatric, cognitive and sexual impairment and impact on professional life retrieved from the AFIRMM questionnaire

\begin{tabular}{|c|c|c|c|c|c|}
\hline \multirow[t]{2}{*}{ Symptom } & \multirow[t]{2}{*}{ N (\%) } & \multicolumn{4}{|l|}{ Severity } \\
\hline & & Mild (\%) & Moderate (\%) & Severe (\%) & $\begin{array}{l}\text { Intolerable } \\
(\%)\end{array}$ \\
\hline Headache & $65(55)$ & 48 & 37 & 14 & 1 \\
\hline Vertigo & $38(32)$ & 60 & 29 & 8 & 3 \\
\hline Irritability & $64(54)$ & 60 & 33 & 6 & 1 \\
\hline Memory loss episodes & $62(52)$ & 70 & 13 & 17 & 0 \\
\hline Difficulty concentrating & $48(40)$ & 56 & 30 & 14 & 0 \\
\hline Sexual impairment & $27(24)$ & 44 & 33 & 19 & 4 \\
\hline Impact on professional life & $29(26)$ & 20 & 35 & 38 & 7 \\
\hline
\end{tabular}


moderate in the majority of patients. Sexual impairment was noted in $24 \%$ of patients. Out of those, sexual impairment was considered severe or intolerable in $23 \%$ of cases. Anti-histamine treatment was associated to headaches (RR 1.5952; 95\% CI 1.1719-2.1715) and fatigue (RR 2.1217; 95\% CI 1.1236-4.0063) but not to other neurological, psychiatric and cognitive symptoms.

No associations were found between neuropsychiatric/ cognitive impairment and age, gender, diagnostic delay, disease form (ICM or SM), the presence of cutaneous lesions, the level of serum and medullar tryptase and the presence of KIT mutation in BM and/or skin (Table 2).

There was no association between neuropsychiatric / cognitive impairment and the presence of MC mediatorrelated systemic symptoms, except for headaches (RR 1.9897; 95\% CI 1.0112-3.9152).

The Hamilton questionnaire was administered to 108/139 patients (78\%). The median score was 8.63 [range 0,30]. Depression was noted in almost half of patients (49\%) and was mild in $33.3 \%$ of patients and moderate and severe in $7.4 \%$ and $5.6 \%$ of patients, respectively. A total of seven patients with a Hamilton score $<8$ (no depression) were undergoing antidepressant therapy (6.5\%).

Patients with urinary symptoms had a higher prevalence of depression (60\%) compared to patients without such symptoms (30\%) (RR 1.5060; 95\% CI 1.0109-2.2434). The same finding was observed for gastro-intestinal symptoms (48\% vs $22 \%$; RR 1.7398 ; $95 \%$ CI $1.1376-2.6606)$ and fatigue (50\% Vs 30\%; RR 1.5678; $95 \%$ CI 1.0891-2.2569).
Depression was also associated with cognitive ( $R R$ 4.2524; 95\% CI 2.0040-9.0233), sexual (RR 1.9076; 95\% CI 1.3546-2.6863) and neurological symptoms (RR 2.6699; 95\% CI 1.4670-4.8592).

One in 4 patients declared that the disease had a negative impact on their professional life. This effect was considered severe or intolerable in $45 \%$ of cases.

This impact on professional life was more prevalent in patients with gastro-intestinal symptoms, cardiovascular symptoms, urinary tract symptoms, cognitive symptoms, depression and fatigue (Fig. 1).

\section{Discussion}

Our current study indicates that mastocytosis patients have a high prevalence of potentially disabling symptoms. Among patients not receiving anti-depressant therapies, some $49 \%$ were depressed according to an analysis based on the Hamilton score. Headaches were also noted in one out of two patients of our cohort and were associated to anti-histamine treatment. Episodes of vertigo were noted in one out of every three patients. Cognitive and sexual impairment were also prevalent, affecting up to $50 \%$ and $25 \%$ of patients, respectively. No association between the latter symptoms and anti-histamine treatment was noted. In addition, one in four patients reported a negative impact on their professional life.

Depression was associated with cognitive, sexual, urinary, gastro-intestinal symptoms and fatigue. However, no associations were detected between depression and cutaneous, respiratory, and cardio-vascular symptoms. As the majority of patients were receiving

Table 2 Association between symptoms and epidemiological, clinical and laboratory parameters

\begin{tabular}{|c|c|c|c|c|c|}
\hline & Depression & Irritability & Neurological symptoms & Cognitive symptoms & Sexual symptoms \\
\hline $\begin{array}{l}\text { Median age } \\
\text { RR }(95 \% \mathrm{Cl})\end{array}$ & $\begin{array}{l}1.2539 \\
(0.8511-1.8475)\end{array}$ & 0.9307 (0.6903-1.2549) & $\begin{array}{l}0.9179 \\
(0.7107-1.1855)\end{array}$ & $1.1670(0.8886-1.5327)$ & $\begin{array}{l}1.2591 \\
(0.6741-2.3516)\end{array}$ \\
\hline $\begin{array}{l}\text { Frequency of male } \\
\operatorname{RR}(95 \% \mathrm{Cl})\end{array}$ & $\begin{array}{l}0.6774 \\
(0.4508-1.0177)\end{array}$ & $\begin{array}{l}1.2212 \\
(0.9079-1.6427)\end{array}$ & $\begin{array}{l}0.8206 \\
(0.6265-1.0748)\end{array}$ & $\begin{array}{l}1.0521 \\
(0.8031-1.3783)\end{array}$ & $\begin{array}{l}1.1754 \\
(0.6308-2.1905)\end{array}$ \\
\hline $\begin{array}{l}\text { Median diagnostic delay } \\
\text { RR }(95 \% \mathrm{Cl})\end{array}$ & $\begin{array}{l}1.0833 \\
(0.7339-1.5989)\end{array}$ & $\begin{array}{l}0.9307 \\
(0.6903-1.2549)\end{array}$ & $\begin{array}{l}1.0940 \\
(0.8456-1.4153)\end{array}$ & $0.9805(0.7484-1.2845)$ & $\begin{array}{l}0.9375 \\
(0.5028-1.7480)\end{array}$ \\
\hline $\begin{array}{l}\text { Frequency of cutaneous } \\
\text { lesions } \\
\text { RR }(95 \% \mathrm{Cl})\end{array}$ & $\begin{array}{l}1.1761 \\
(0.7263-1.9045)\end{array}$ & $\begin{array}{l}1.0762 \\
(0.7259-1.5955)\end{array}$ & $\begin{array}{l}1.2107 \\
(0.9047-1.6203)\end{array}$ & $1.2483(0.9257-1.6834)$ & $0.9060(0.3587-2.2883)$ \\
\hline $\begin{array}{l}\text { Mastocytosis form } \\
\text { RR }(95 \% \mathrm{Cl})\end{array}$ & $\begin{array}{l}1.3578 \\
(0.7589-2.4293)\end{array}$ & $\begin{array}{l}0.8290 \\
(0.5963-1.1525)\end{array}$ & $\begin{array}{l}0.9983 \\
(0.7203-1.3836)\end{array}$ & $\begin{array}{l}0.9809 \\
(0.6987-1.3770)\end{array}$ & $\begin{array}{l}1.2000 \\
(0.5126-2.8092)\end{array}$ \\
\hline $\begin{array}{l}\text { Serum tryptase level } \\
\text { RR }(95 \% \mathrm{Cl})\end{array}$ & $\begin{array}{l}1.3102 \\
(0.8051-2.1322)\end{array}$ & $\begin{array}{l}1.0190 \\
(0.7295-1.4233)\end{array}$ & $\begin{array}{l}1.0989 \\
(0.8198-1.4730)\end{array}$ & $\begin{array}{l}1.1585 \\
(0.8453-1.5878)\end{array}$ & $0.7814(0.4136-1.4761)$ \\
\hline $\begin{array}{l}\text { Bone marrow tryptase level } \\
\text { RR }(95 \% \mathrm{Cl})\end{array}$ & $\begin{array}{l}0.9863 \\
(0.6554-1.4843)\end{array}$ & $\begin{array}{l}1.0470 \\
(0.7427-1.4759)\end{array}$ & $\begin{array}{l}1.0628 \\
(0.7973-1.4165)\end{array}$ & $\begin{array}{l}1.1596 \\
(0.8355-1.6094)\end{array}$ & $\begin{array}{l}0.7429 \\
(0.3926-1.4058)\end{array}$ \\
\hline $\begin{array}{l}\text { KIT mutation status in BM } \\
\text { RR }(95 \% \mathrm{Cl})\end{array}$ & $\begin{array}{l}1.1780 \\
(0.7063-1.9650)\end{array}$ & $\begin{array}{l}0.9278 \\
(0.6591-1.3060)\end{array}$ & $\begin{array}{l}0.9968 \\
(0.7378-1.3467\end{array}$ & $\begin{array}{l}1.0833 \\
(0.7641-1.5358)\end{array}$ & $\begin{array}{l}0.7704 \\
(0.3856-1.5392)\end{array}$ \\
\hline $\begin{array}{l}\text { KIT mutation frequency in skin } \\
\text { RR }(95 \% \mathrm{Cl})\end{array}$ & $\begin{array}{l}0.9267 \\
(0.6020-1.4265)\end{array}$ & $\begin{array}{l}0.8741 \\
(0.6377-1.1982)\end{array}$ & $\begin{array}{l}0.9135 \\
(0.6940-1.2023)\end{array}$ & $\begin{array}{l}0.9687 \\
(0.7170-1.3086)\end{array}$ & $\begin{array}{l}1.1560 \\
(0.5473-2.4418)\end{array}$ \\
\hline
\end{tabular}




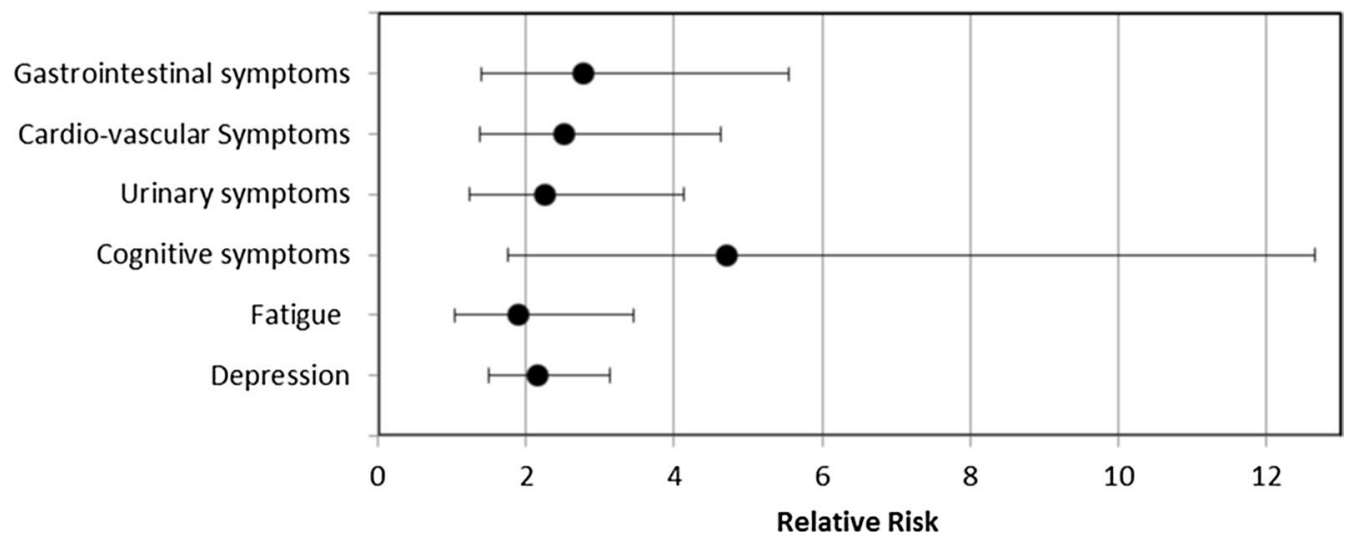

Fig. 1 The relation between the impact on professional life and gastro-intestinal, cardiovascular, urinary tract and cognitive symptoms, depression and fatigue

anti-histamines, and montelukast treatment at the time of completing the questionnaire, this may have reduced our ability to detect an association.

The prevalence of neurological, cognitive, sexual, and psychiatric symptoms (including depression) was similar in patients with cutaneous and systemic mastocytosis. Symptoms were not influenced by indicators of total MC burden such as serum or medullar tryptase level [9-11]. There were not associations between symptoms and the presence of KIT mutations.

There is limited data about the frequency of neuro-cognitive, psychiatric, and sexual impairment in mastocytosis patients. Two previous studies reported the prevalence of neurological symptoms in mastocytosis patients [12, 13]. Headaches were the most prevalent symptom affecting some 35 to $56 \%$ of patients. Experiencing a headache was associated with an increased prevalence of other MC mediator-related systemic symptoms [12].

Cognitive impairment was first reported by Soter et al. in five out of eight mastocytosis patients [14]. In another small study, ten patients underwent psychiatric interviews and a battery of psychological testing. Out of these, eight presented with cognitive and affective changes categorised as mixed organic brain syndrome [15]. In another study 22 out of 57 mastocytosis patients (38.6\%) presented with memory/concentration impairment. This cognitive impairment was not related to depression, age or the type of mastocytosis [16]. Our current study, of a larger cohort $(n=139)$, reports a higher prevalence of cognitive impairments such as memory loss and difficulty concentrating in $52 \%$ and $40 \%$ of patients, respectively. We also observed an association between cognitive symptoms and depression, urinary and gastro-intestinal symptoms, and fatigue but not with age. Although depression and cognitive impairments are common co-morbidities, understanding their relationship remains limited [17].

In terms of mood disorders, Roger et al. diagnosed depression from psychiatric interviews in four mastocytosis patients out of ten [15]. This was further investigated in two other studies. The first of these studies calculated a HAMILTON score for 88 patients and found that $75 \%$ of patients had scores of $\geq 10$ [6]. The second study, involving 288 patients, reported $56 \%$ of patients with a HAMILTON Score between 8 and 22 which was categorised as mild-moderate depression based on the cut-offs used in that study [18]. In contrast to our study, these two previous studies did not assess associations between depression and other mastocytosis symptoms. The Moura et al. study showed that mastinib treatment, a tyrosine kinase inhibitor which decreases disease burden, also improved depression scores. Interestingly, this improvement was unrelated to the improvement in overall quality of life. This is also consistent with a phase 2a multicentre study which evaluated the effect of masitinib treatment in 25 mastocytosis patients and showed a $>50 \%$ improvement in Hamilton scores compared to baseline [19]. Improvement in depression could be related to the inhibitory effect of masitinib on MC activation which would support the assumption that depression is a systemic manifestation of the disease [20].

The frequency of depression in mastocytosis patients appears to be higher to what might be expected in the general population (7\%) and in patients with advanced chronic conditions such as cancer $(10-15 \%)$ and diabetes (14-25\%) [21-24].

This raises the question of whether neurological, affective, and cognitive impairment is the result of primitive $\mathrm{MC}$ infiltration of the brain or the effects of $\mathrm{MC}$ mediators. 
Boddaert et al. reported morphological brain abnormalities consisting on abnormal punctuated white matter hyper signals in $49 \%$ of mastocytosis patients with psycho-cognitive complaints. As no histological diagnosis was done in this study, no evidence of MCs infiltration of the brain could be found. The authors suggested the implication of MC mediators without MC infiltrates in the recruitment and the proliferation of inflammatory cells resulting in neuroimaging abnormalities and neurocognitive symptoms [25].

Indeed some experimental evidence suggests that $\mathrm{MC}$ mediators may contribute to headaches, depression, and cognitive impairment.

Degranulation of dural mast cells induces activation of the trigeminal pain pathway believed to underpin migraine headaches [25]. Histamine, leukotrienes, TNFalpha, IL- 6 and endothelin-1 released from MCs have been implicated in the pathophysiology of migraines [26-28].

A study of fifty-four mastocytosis patients has also suggested a role for MCs in the tryptophan catabolic pathway which is involved in depression. Alterations in tryptophan and serotonin metabolism, which are implicated in depression pathogenesis, have also been demonstrated in mastocytosis patients [29]

The implication of pro-inflammatory cytokines and MC-derived inflammatory mediators in neuro-inflammation and neurodegeneration could also explain the cognitive impairment in mastocytosis [30]. The degranulation of MCs and the release of histamine [31] activate microglia through histamine receptors $\mathrm{H} 1$ and $\mathrm{H} 4$ and release neurotoxic mediators such as IL-1b, TNF-alpha, IL-6, and nitric oxide (NO) [32]. These pro-inflammatory mediators directly induce neuronal death in the brain. Inflammatory cytokines such as IL-1b are known to induce neurodegeneration [33].

We therefore suspect that these symptoms are the result of mast cell activation and the systemic release of mediators rather than due to the proliferation or infiltration of MCs. This hypothesis is also sustained by the lack of impact of the type of mastocytosis (cutaneous or systemic) on these symptoms.

Regarding the impact of the disease on patients' professional lives (which affects $26 \%$ of patients in our study), it appears to be noticeably higher than what had been reported in one previous study (15\%) [34]. This emphasises the importance of disease burden in mastocytosis patients. In our cohort, this impact was associated with psycho-cognitive impairment, gastro-intestinal, cardiovascular, and urinary symptoms, and fatigue.

The patient's perception of disability was assessed in a cohort of 62 patients with a confirmed mastocytosis diagnosis. Perceived handicap was noted in $87 \%$ of patients and was scored as moderate to severe in $52 \%$ of patients. In the same study, psychological, sexual, cognitive and neurological symptoms were found to be key contributors to disability in mastocytosis [6].

Our study is the first, to our knowledge, to simultaneously evaluate the neurological, cognitive, and emotional impacts of mastocytosis, which highlights the high degree of patient distress. There is an urgent need for physicians to recognise and treat neuro-psychiatric and cognitive symptoms associated with mastocytosis and to better understand the impact of such symptoms on the lives of their patients.

Our study has some limitations which are essentially due to its retrospective and monocentric nature. The available clinical data also did not allow us to assess the different headache subtypes. To assess depression, we used a validated measure and not a structured diagnostic interview which is generally considered the gold standard to detect depression.

We also only assessed subjective cognitive impairment and did not use objective instruments to evaluate this type of impairment in our mastocytosis patients.

\section{Conclusion}

Our current study provides some insights regarding symptoms related to mastocytosis and their impact on patients' professional lives. Further research is needed to evaluate the link between MCs and neuro-psychiatric, cognitive, and sexual symptoms.

\section{Abbreviations \\ MCs: Mast cells; MC: Mast cell; ICM: Isolated cutaneous mastocytosis; SM: Systemic mastocytosis; AFIRMM: Association Française pour les Initiatives et la Recherche sur le Mastocyte et les Mastocytoses; HDRS-17: 17-Item version of the Hamilton Depression Rating Scale; BM: Bone marrow; NO: Nitric oxide.}

\section{Acknowledgements}

Not applicable.

\section{Authors' contributions}

FJ: drafted the article; MN: performed the statistical analysis; MS-F, CA, CP and CBL: critically revised the work. All authors read and approved the final manuscript.

\section{Funding}

Authors received no funds for this article.

\section{Availability of data and materials}

The datasets generated and/or analysed during the current study are not publicly available due data size but are available from the corresponding author on reasonable request.

\section{Ethics approval and consent to participate}

The study was approved by the Institutional Review Board of the Necker Enfants-Malades Hospital on November 8, 2000 (RC31/17/0095) and was carried out in accordance with the Declaration of Helsinki.

Consent for publication

All patients gave their written informed consent. 


\section{Competing interests}

Fatma Jendoubi, Mathilde Negretto, Maella Severino-Freire, Christophe Arbus, Cristina Bulai Livideanu and Carle Paul declare they have no conflict of interest regarding this epidemiological study.

\section{Author details}

${ }^{1}$ Mastocytosis National Expert Centre (CEREMAST), Department of Dermatology, Toulouse University Hospital, 24 Chemin de Pouvourville, 31059 Toulouse, France. ${ }^{2}$ Department of Psychiatry, Toulouse University Hospital, Tonic Inserm 1214, Toulouse, France.

Received: 19 October 2020 Accepted: 16 February 2021

Published online: 05 March 2021

\section{References}

1. Valent P, Akin C, Arock M, Brockow K, Butterfield JH, Carter MC, et al. Definitions, criteria and global classification of mast cell disorders with special reference to mast cell activation syndromes: a consensus proposal. Int Arch Allergy Immunol. 2012;157(3):215-25.

2. Cohen S, Skovbo S, Vestergaard H, Kristensen T, Møller M, Bindslev-Jensen C, Fryzek J, Broesby-Olsen S. Epidemiology of systemic mastocytosis in Denmark. Br J Haematol. 2014;166(4):521-8.

3. Fradet M, Negretto M, Tournier E, Laurent C, Apoil PA, Evrard S, et al. Frequency of isolated cutaneous involvement in adult mastocytosis: a cohort study. J Eur Acad Dermatol Venereol. 2019;33(9):1713-8.

4. Valent P, Akin C, Metcalfe DD. Mastocytosis: 2016 updated WHO classification and novel emerging treatment concepts. Blood. 2017;129(11):1420-7.

5. Siebenhaar F, von Tschirnhaus E, Hartmann K, Rabenhorst A, Staubach P, Peveling-Oberhag A, et al. Development and validation of the mastocytosis quality of life questionnaire: MC-QoL. Allergy. 2016;71(6):869-77.

6. Hermine O, Lortholary O, Leventhal PS, Catteau A, Soppelsa F, Baude C, et al. Case-control cohort study of patients' perceptions of disability in mastocytosis. PLoS ONE. 2008;3(5):e2266.

7. Hamilton M. A rating scale for depression. J Neurol Neurosurg Psychiatry. 1960;23:56-62.

8. Zimmerman M, Martinez JH, Young D, Chelminski I, Dalrymple K. Severity classification on the Hamilton Depression Rating Scale. J Affect Disord. 2013;150(2):384-8.

9. Schwartz LB. Diagnostic value of tryptase in anaphylaxis and mastocytosis. Immunol Allergy Clin North Am. 2006;26(3):451-63.

10. Proelss J, Wenzel J, Ko Y, Bieber T, Bauer R. Tryptase detection in bonemarrow blood: a new diagnostic tool in systemic mastocytosis. J Am Acad Dermatol. 2007:56(3):453-7.

11. Bulai Livideanu C, Apoil PA, Lepage B, Eischen M, Laurent C, Laharrague $P$, et al. Bone marrow tryptase as a possible diagnostic criterion for adult systemic mastocytosis. Clin Exp Allergy. 2016;46(1):133-41.

12. Smith $\mathrm{JH}$, Butterfield $\mathrm{J}, \mathrm{H}$, Cutrer FM. Primary headache syndromes in systemic mastocytosis. Cephalalgia. 2011;31(15):1522-31.

13. Smith JH, Butterfield JH, Pardanani A, DeLuca GC, Cutrer FM. Neurologic symptoms and diagnosis in adults with mast cell disease. Clin Neurol Neurosurg. 2011;113(7):570-4.

14. Soter NA, Austen KF, Wasserman SI. Oral disodium cromoglycate in the treatment of systemic mastocytosis. N Engl J Med. 1979;301(9):465-9.

15. Rogers MP, Bloomingdale K, Murawski BJ, Soter NA, Reich P, Austen KF. Mixed organic brain syndrome as a manifestation of systemic mastocytosis. Psychosom Med. 1986;48(6):437-47.

16. Moura DS, Sultan S, Georgin-Lavialle S, Barete S, Lortholary O, Gaillard $\mathrm{R}$, et al. Evidence for cognitive impairment in mastocytosis: prevalence, features and correlations to depression. PLOS ONE. 2012;7(6):e39468.

17. Castaneda AE, Tuulio-Henriksson A, Marttunen M, Suvisaari J, Lonnqvist J. A review on cognitive impairments in depressive and anxiety disorders with a focus on young adults. J Affect Disord. 2008;106(1-2):1-27.
18. Moura DS, Sultan S, Georgin-Lavialle S, Pillet N, Montestruc F, Gineste P, et al. Depression in patients with mastocytosis: prevalence, features and effects of masitinib therapy. PLoS ONE. 2011;6(10):e26375.

19. Paul C, Sans B, Suarez F, Casassus P, Barete S, Lanternier F, et al. Masitinib for the treatment of systemic and cutaneous mastocytosis with handicap: a phase 2a study. Am J Hematol. 2010;85(12):921-5.

20. Miller $\mathrm{AH}$, Maletic $\mathrm{V}$, Raison $\mathrm{CL}$. Inflammation and its discontents: the role of cytokines in the pathophysiology of major depression. Biol Psychiatry. 2009;65(9):732-41.

21. Laugsand EA, Sprangers MA, Bjordal K, Skorpen F, Kaasa S, Klepstad P. Health care providers underestimate symptom intensities of cancer patients: a multicenter European study. Health Qual Life Outcomes. 2010;8:104.

22. Stiefel F, Die Trill M, Berney A, Olarte JM, Razavi A. Depression in palliative care: a pragmatic report from the Expert Working Group of the European Association for Palliative Care. Support Care Cancer. 2001;9(7):477-88.

23. Brintzenhofe-Szoc KM, Levin TT, Li Y, Kissane DW, Zabora JR. Mixed anxiety/depression symptoms in a large cancer cohort: prevalence by cancer type. Psychosomatics. 2009;50(4):383-91.

24. Sultan S, Hartemann-Heurtier A, Grimaldi A. Understanding patients to promote self-regulation in Type 2 diabetes: how to live with an illness beginning before its onset? Diabetes Metab. 2003;29(2 Pt 3):S21-30.

25. Boddaert N, Salvador A, Chandesris MO, Lemaître H, Grévent D, Gauthier C, Naggara O, Georgin-Lavialle S, Moura DS, Munsch F, Jaafari N, Zilbovicius M, Lortholary O, Gaillard R, Hermine O. Neuroimaging evidence of brain abnormalities in mastocytosis. Transl Psychiatry. 2017;7(8):e1197.

26. Levy D, Burstein R, Kainz V, Jakubowski M, Strassman AM. Mast cell degranulation activates a pain pathway underlying migraine headache. Pain. 2007;130(1-2):166-76.

27. Hasselblatt M, Kohler J, Volles E, Ehrenreich H. Simultaneous monitoring of endothelin-1 and vasopressin plasma levels in migraine. NeuroReport. 1999;10(2):423-5

28. Sheftell F, Rapoport A, Weeks R, Walker B, Gammerman I, Baskin S. Montelukast in the prophylaxis of migraine: a potential role for leukotriene modifiers. Headache. 2000;40(2):158-63.

29. Sarchielli P, Alberti A, Baldi A, Coppola F, Rossi C, Pierguidi L, et al. Proinflammatory cytokines, adhesion molecules, and lymphocyte integrin expression in the internal jugular blood of migraine patients without aura assessed ictally. Headache. 2006;46(2):200-7.

30. Georgin-Lavialle S, Moura DS, Salvador A, Chauvet-Gelinier JC, Launay JM, Damaj G, et al. Mast cells' involvement in inflammation pathways linked to depression: evidence in mastocytosis. Mol Psychiatry. 2016;21(11):1511-6.

31. Kempuraj D, Selvakumar GP, Thangavel R, Ahmed ME, Zaheer S, Raikwar $S P$, et al. Mast cell activation in brain injury, stress, and post-traumatic stress disorder and Alzheimer's disease pathogenesis. Front Neurosci. 2017;11:703.

32. Purcell WM, Westgate C, Atterwill CK. Rat brain mast cells: an in vitro paradigm for assessing the toxic effects of neurotropic therapeutics. Neurotoxicology. 1996;17(3-4):845-50.

33. Dong $H$, Zhang W, Zeng $X, H u ~ G$, Zhang H, He S, et al. Histamine induces upregulated expression of histamine receptors and increases release of inflammatory mediators from microglia. Mol Neurobiol. 2014;49(3):1487-500.

34. Rothwell NJ, Luheshi GN. Interleukin 1 in the brain: biology, pathology and therapeutic target. Trends Neurosci. 2000;23(12):618-25.

35. Jennings S, Russell N, Jennings B, Slee V, Sterling L, Castells M, et al. The Mastocytosis Society survey on mast cell disorders: patient experiences and perceptions. J Allergy Clin Immunol Pract. 2014;2(1):70-6.

\section{Publisher's Note}

Springer Nature remains neutral with regard to jurisdictional claims in published maps and institutional affiliations. 